\title{
CO-dependent hydrogen production by the facultative anaerobe Parageobacillus thermoglucosidasius
}

\author{
Teresa Mohr ${ }^{1,4^{*}} \mathbb{0}$, Habibu Aliyu', Raphael Küchlin', Shamara Polliack², Michaela Zwick', Anke Neumann', \\ Don Cowan ${ }^{2}$ and Pieter de Maayer ${ }^{3}$
}

\begin{abstract}
Background: The overreliance on dwindling fossil fuel reserves and the negative climatic effects of using such fuels are driving the development of new clean energy sources. One such alternative source is hydrogen $\left(\mathrm{H}_{2}\right)$, which can be generated from renewable sources. Parageobacillus thermoglucosidasius is a facultative anaerobic thermophilic bacterium which is frequently isolated from high temperature environments including hot springs and compost.

Results: Comparative genomics performed in the present study showed that $P$. thermog/ucosidasius encodes two evolutionary distinct $\mathrm{H}_{2}$-uptake [Ni-Fe]-hydrogenases and one $\mathrm{H}_{2}$-evolving hydrogenases. In addition, genes encoding an anaerobic $\mathrm{CO}$ dehydrogenase $(\mathrm{CODH})$ are co-localized with genes encoding a putative $\mathrm{H}_{2}$-evolving hydrogenase. The co-localized of $\mathrm{CODH}$ and uptake hydrogenase form an enzyme complex that might potentially be involved in catalyzing the water-gas shift reaction $\left(\mathrm{CO}+\mathrm{H}_{2} \mathrm{O} \rightarrow \mathrm{CO}_{2}+\mathrm{H}_{2}\right)$ in P. thermoglucosidasius. Cultivation of $P$. thermoglucosidasius DSM $2542^{\top}$ with an initial gas atmosphere of $50 \%$ CO and $50 \%$ air showed it to be capable of growth at elevated CO concentrations (50\%). Furthermore, GC analyses showed that it was capable of producing hydrogen at an equimolar conversion with a final yield of $1.08 \mathrm{H}_{2} / \mathrm{CO}$.
\end{abstract}

Conclusions: This study highlights the potential of the facultative anaerobic $P$. thermoglucosidasius DSM $2542^{\top}$ for developing new strategies for the biohydrogen production.

Keywords: Biohydrogen production, Parageobacillus thermoglucosidasius, Carbon monoxide dehydrogenase, Hydrogenase, Water-gas shift reaction

\section{Background}

In the next 30 years, the global energy demand will expand by ca. $30 \%$ and the vast majority (ca. $85 \%$ ) of the energy resources required to offset the rising demand will come from non-renewable sources such as natural gas and crude oil [1]. This will result in increased pressure on the dwindling fossil fuel reserves and in greater emission of greenhouse gases into the Earth's atmosphere. There is thus an urgent need for further development and implementation of clean and renewable alternative energy sources [2,3].

\footnotetext{
*Correspondence: teresa.mohr@kit.edu

${ }^{4}$ Section II: Technical Biology, Institute of Process Engineering in Life

Science, Karlsruhe Institut für Technologie (KIT), Kaiserstrasse 12,

76131 Karlsruhe, Germany

Full list of author information is available at the end of the article
}

Hydrogen $\left(\mathrm{H}_{2}\right)$ has recently become prominent as a very attractive clean and sustainable energy source, especially when generated via 'eco-friendly' strategies. In comparison to other fuels, $\mathrm{H}_{2}$ has the highest energy content (141.9 MJ/kg higher heating value) [2]. Additionally, its complete combustion with pure oxygen produces only water $\left(2 \mathrm{H}_{2}+\mathrm{O}_{2} \rightarrow 2 \mathrm{H}_{2} \mathrm{O}\right)$ as a by-product. The majority of current industrial $\mathrm{H}_{2}$ production strategies, such as coal gasification, steam reformation and partial oxidation of oil, are unsustainable, harmful to the environment, energy intensive and expensive [4, 5]. As such, over the past few years, the production of $\mathrm{H}_{2}$ via microbial catalysis has drawn increasing interest. Several different strategies to produce biohydrogen, such as photofermentation of organic substances 
by photosynthetic bacteria, bio-photolysis of water by algae and dark fermentation of organic substances by anaerobic microorganism, have been explored [6]. These strategies have the advantage of lower energy expenditure, lower cost and higher yields than the industrial methods [7]. Another advantage is the potential to use cheap feedstocks, such as lignocellulosic waste biomass, which can be converted into a gas mixture termed 'synthesis gas'. This gas consists primarily of carbon monoxide $(\mathrm{CO})$, carbon dioxide $\left(\mathrm{CO}_{2}\right)$ and $\mathrm{H}_{2}$ [8]. In a further step, the $\mathrm{CO}$ can react with water to generate $\mathrm{H}_{2}$ via a biologically- or chemically-mediated water-gas shift (WGS) reaction: $\mathrm{CO}+\mathrm{H}_{2} \mathrm{O} \rightarrow \mathrm{CO}_{2}+\mathrm{H}_{2}$. During the biologically mediated reaction, a carbon monoxide dehydrogenase $(\mathrm{CODH})$ oxidizes $\mathrm{CO}$ and electrons are released. Subsequently, a coupled hydrogenase reduces the released electrons to molecular hydrogen [9]. Several mesophilic, anaerobic prokaryotic taxa, including Rhodospirillum rubrum and Rhodopseudomonas palustris, are known for the ability to perform the WGS reaction [10].

It has been observed that higher yields of $\mathrm{H}_{2}$ can be obtained in higher temperature fermentations [11]. Thus, there has been increasing interest in the use of thermophilic anaerobic bacteria, such as Carboxydothermus hydrogenoformans and Thermosinus carboxydivorans [12, 13], as well thermophilic archaea (e.g. Thermococcus onnurineus) [7].

An industrial process utilizing $\mathrm{CO}$-oxidizing bacteria for biohydrogen production has not yet been realized, although many $\mathrm{CO}$-using hydrogenogenic species have been isolated. This may largely be attributed to the sensitivity of both the hydrogenase and CODH enzymes to oxygen $[6,14]$. For example, the hydrogenase of Thermotoga maritima lost $80 \%$ of its activity after flushing with air for $10 \mathrm{~s}$ [15]. Removal of $\mathrm{O}_{2}$ from industrial waste gases or from bioreactors is prohibitively expensive, making the use of strictly anaerobic CO-oxidizing hydrogenogens unfeasible [16]. Here, we have analysed the hydrogenogenic capacity of the facultative anaerobe Parageobacillus thermoglucosidasius. Comparative genomics revealed the presence of three distinct hydrogenases, two uptake hydrogenases as well as one $\mathrm{H}_{2}$-evolving hydrogenase, which is linked to an anaerobic CODH. Evolutionary analysis showed that this combination of hydrogenases is unique to $P$. thermoglucosidasius and suggests that $\mathrm{H}_{2}$ plays a pivotal in the bioenergetics of this organism. Furthermore, fermentations and downstream GC analysis showed that this facultative anaerobe is capable of utilizing $\mathrm{CO}$ in the WGS reaction to generate an equimolar amount of $\mathrm{H}_{2}$ once most of the oxygen in the medium has been exhausted.

\section{Methods}

\section{Microorganisms}

The production of $\mathrm{H}_{2}$ by $P$. thermoglucosidasius when grown in the presence of $\mathrm{CO}$ was tested using $P$. thermoglucosidasius DSM $2542^{\mathrm{T}}$. Two related strains, Geobacillus thermodenitrificans DSM $465^{\mathrm{T}}$ and P. toebii DSM $14590^{\mathrm{T}}$, which lack orthologues of the three hydrogenase loci as well as the $\mathrm{CODH}$ locus, were included as controls. All strains were obtained from the DSMZ (Deutsche Sammlung von Mikroorganismen und Zellkulturen GmbH, Braunschweig, Germany).

\section{Culture conditions and media}

Pre-cultures and cultures were grown aerobically in mLB (modified Luria-Bertani) medium containing tryptone $(1 \% \mathrm{w} / \mathrm{v})$, yeast extract $(0.5 \% \mathrm{w} / \mathrm{v}), \mathrm{NaCl}(0.5 \%$ $\mathrm{w} / \mathrm{v}), 1.25 \mathrm{ml} / \mathrm{l} \mathrm{NaOH}(10 \% \mathrm{w} / \mathrm{v})$, and $1 \mathrm{ml} / \mathrm{l}$ of each of the filter-sterilized stock solutions: $1.05 \mathrm{M}$ nitrilotriacetic acid, $0.59 \mathrm{M} \mathrm{MgSO}_{4} \cdot 7 \mathrm{H}_{2} \mathrm{O}, 0.91 \mathrm{M} \mathrm{CaCl}_{2} \cdot 2 \mathrm{H}_{2} \mathrm{O}$ and $0.04 \mathrm{M} \mathrm{FeSO}_{4} \cdot 7 \mathrm{H}_{2} \mathrm{O}$. The first pre-culture was inoculated from glycerol stock $(20 \mu \mathrm{l}$ in $20 \mathrm{ml} \mathrm{mLB})$ and cultivated for $24 \mathrm{~h}$ at $60^{\circ} \mathrm{C}$ and rotation at $120 \mathrm{rpm}$ in an Infors Thermotron (Infors AG, Bottmingen, Switzerland). A second pre-culture was inoculated from the first one to an $\mathrm{OD}_{600}$ of 0.1 and incubated as above for $12 \mathrm{~h}$. For the experiments, $250 \mathrm{ml}$ serum bottles were prepared with $50 \mathrm{ml} \mathrm{mLB}$ and a gas phase of $50 \% \mathrm{CO}$ and $50 \%$ atmospheric air at 1 bar atmospheric pressure, which were inoculated with $1 \mathrm{ml}$ from the second preculture. The experiments were conducted in quadruplicate for a total duration of $84 \mathrm{~h}$.

\section{Analytical methods}

Samples were taken at different time points during the experimental procedure. Before and after the sampling the pressure was measured using a manometer (GDH 14 AN, Greisinger electronic, Regenstauf, Germany). To monitor the growth of the cultures, $1 \mathrm{ml}$ of the culture was aspirated through the stopper and absorbance was measured at $\mathrm{OD}_{600}$ using an Ultrospec 1100 pro spectrophotometer (Amersham Biosciences, USA). The determination of the gas compositions at different time points was conducted using a 3000 Micro GC gas analyzer (Inficon, Bad Ragaz, Switzerland) with the columns Molsieve and PLOT Q. A total of $3 \mathrm{ml}$ was sampled from the head space and injected into the GC. A constant temperature of $80{ }^{\circ} \mathrm{C}$ was maintained during the total analysis time of $180 \mathrm{~s}$. The gas compositions at the different sampling points were calculated using the formulas in Additional file 1. 


\section{Comparative genomic analyses}

The large hydrogenase subunits were identified from the annotated genome of $P$. thermoglucosidasius DSM $2542^{\mathrm{T}}$ (CP012712.1) by comparison against the Hydrogenase DataBase (HyDB) [17]. The full hydrogenase loci were identified by searching the genome up- and downstream of the large subunit gene, extracted and mapped against the genome using the CGView server [18]. The proteins encoded on the genome were compared by BlastP against the NCBI non-redundant (nr) protein database to identify orthologous loci. Full loci were extracted from the comparator genomes and all loci were structurally annotated using Genemark.hmm prokaryotic v.2 [19]. The resultant protein datasets were compared by local BlastP with Bioedit v 7.2.5 [20] to identify orthologues, where orthology was assumed for those proteins sharing $>30 \%$ amino acid identity over $70 \%$ sequence coverage.

A maximum likelihood (ML) phylogeny was constructed based on the amino acid sequences of three commonly used housekeeping markers: translation initiation factor IF-2 (InfB), DNA recombination and repair protein RecN RNA polymerase subunit B (RpoB). The proteins were individually aligned using M-Coffee [21], the alignments concatenated and poorly aligned regions were trimmed using Gblocks [22]. Finally, the trimmed alignment was used to generate a ML phylogeny using PhyML-SMS, using the optimal amino acid substitution model as predicted by the Smart Model Selection tool $[23,24]$. Similarly, ML phylogenies were constructed on the basis of the concatenated orthologous proteins encoded on the Pha, Phb, Phc and CODH loci.

\section{Results}

The genome of $P$. thermoglucosidasius encodes three distinct hydrogenases

Analysis of the complete, annotated genome sequence of P. thermoglucosidasius DSM $2542^{\mathrm{T}}$ showed the presence of three putative [Ni-Fe]-hydrogenase loci on the chromosome. Two of these hydrogenases are encoded on the forward strand, while the third is located on the reverse strand (Fig. 1). Given the convoluted nomenclature of hydrogenase genes, we have termed these loci as Parageobacillus hydrogenase $\mathbf{a}, \mathbf{b}$ and $\mathbf{c}$, in accordance with their chromosomal locations), to distinguish between them.

The Pha locus (chromosomal position 2,456,9632,469,832; $12.9 \mathrm{~kb}$ in size) comprises eleven protein coding sequences (NCBI Accession ALF10692-10702; PhaA-PhaK) (Fig. 1; Additional file 2). Comparison of the amino acid sequence of the predicted catalytic subunit (ALF10727-PhaB) against HydDB [17] classifies the hydrogenase produced by this locus as a $[\mathrm{Ni}-\mathrm{Fe}]$ group 1d uptake hydrogenase $(\mathrm{E}$-value $=0.0)$. This unidirectional, membrane-bound, $\mathrm{O}_{2}$-tolerant hydrogenase is present in a broad range of obligately aerobic and facultatively anaerobic soil-borne, aquatic and host-associated taxa such as Ralstonia eutropha, Escherichia coli and Wolinella succinogenes [25, 26]. The $\mathrm{H}_{2}$ molecules consumed by group $1 \mathrm{~d}$ hydrogenases are coupled to aerobic respiration $\left(\mathrm{O}_{2}\right.$ as electron acceptor) or to respiratory reduction of various anaerobic electron acceptors including $\mathrm{NO}^{3-}, \mathrm{SO}_{4}{ }^{2-}$, fumarate and $\mathrm{CO}_{2}$. The $P$. thermoglucosidasius DSM $2542^{\mathrm{T}}$ hydrogenase locus incorporates genes coding for both small (PhaA; ALF10692; 324 aa) and large (PhaB; ALF10693; 573 aa) catalytic hydrogenase subunits. The strain also encodes seven additional proteins involved in hydrogenase formation, maturation and incorporation of the $\mathrm{Ni}$-Fe metallocenter, including a third hydrogenase subunit (PhaC) which is predicted to serve as cytochrome $b$ orthologue and links the hydrogenase to the quinone pools of the respiratory chains (Fig. 1; Additional file 2) [26]. The pha genes are flanked at the $5^{\prime}$ end by two genes coding for orthologues of the Twin-arginine translocation (Tat) pathway proteins TatA and TatC (Fig. 1; Additional file 2). These have been shown to form part of the membrane targeting and translocation (Mtt) pathway which targets the fully folded hydrogenase heterodimer to the membrane [27].

The Phb locus (chromosomal position 2,488,6142,503,714; $15.1 \mathrm{~kb}$ in size), located $\sim 19 \mathrm{~kb}$ downstream of the Pha locus, comprises 16 protein coding sequences (NCBI Accession ALF10723-738; PhbA-PhbP) (Fig. 1; Additional file 2). The predicted catalytic subunit (ALF10727-PhbE) compared against HydDB classifies the product of this locus as a [Ni-Fe] group 2a uptake hydrogenase $(E-v a l u e=0.0)$ [17]. Members of this group of uptake hydrogenases are widespread among aerobic soil bacteria and Cyanobacteria and play a role in recycling $\mathrm{H}_{2}$ produced by nitrogenase activity and fermentative pathways $[28,29]$. The recycled $\mathrm{H}_{2}$ is used in hydrogenotrophic respiration with $\mathrm{O}_{2}$ serving as terminal electron acceptor, and thus group 2a hydrogenases are often $\mathrm{O}_{2}$-tolerant [26]. This locus encodes both large (PhbE; ALF10727; 544 aa) and small (PhbD; ALF10726; 317) [Ni-Fe] hydrogenase subunits and eight additional proteins with predicted roles in hydrogenase formation, maturation and incorporation of the $\mathrm{Ni}-\mathrm{Fe}$ metal center in the large subunit (Fig. 1; Additional file 2) [26]. Furthermore, this locus encodes six proteins whose role in hydrogenase biosynthesis and functioning remains unclear. These include a tetratricopeptide-repeat $(\mathrm{PhbH})$ and NHL repeat (PhbK) containing protein, which also occur in the [Ni-Fe] group 2a hydrogenase loci of Nostoc punctiforme ATCC 29133 and Nostoc sp. PCC 7120, where they are co-transcribed with the hydrogenase 


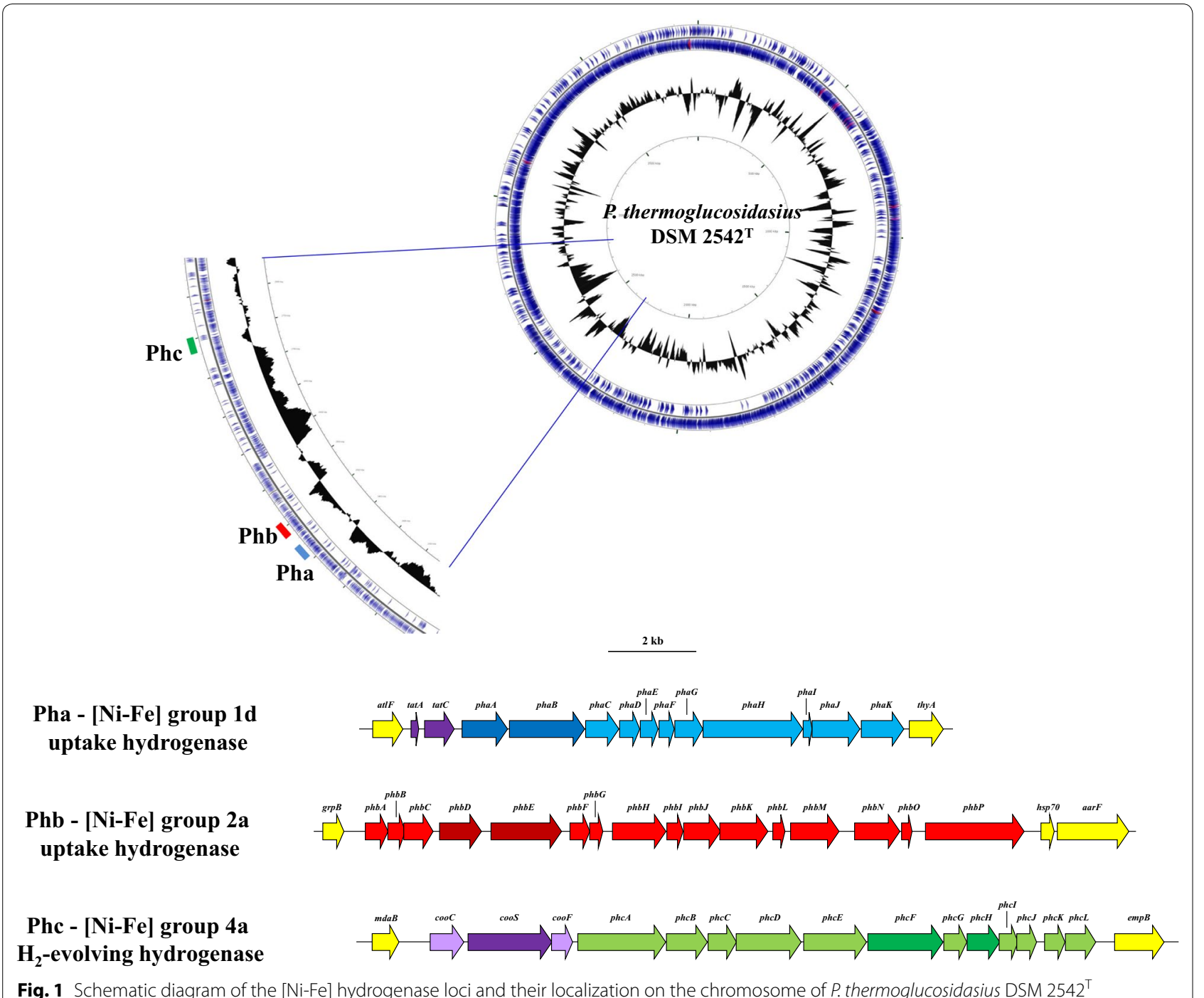

genes and have been suggested to play a role in proteinprotein interactions and $\mathrm{Fe}-\mathrm{S}$ cluster biogenesis (PhbJ) which may mediate electron transport to redox partners in downstream reactions [30].

The Phc locus (chromosomal position 2,729,4892,741,372), $226 \mathrm{~kb}$ downstream of the Phb locus is $11.9 \mathrm{~kb}$ in size and encodes 12 distinct proteins (PhcAPhcL) (Fig. 1; Additional file 2). These include a small (PhcE; ALF10919; 247 aa) and large (PhcG; ALF19021; 574 aa) [Ni-Fe]-hydrogenase catalytic subunit and ten additional proteins involved in hydrogenase formation and maturation (Fig. 1; Additional file 2). The HydDB classifies the Phc hydrogenase as a $[\mathrm{Ni}-\mathrm{Fe}]$ group $4 \mathrm{a}$ hydrogenase or formate hydrogenlyase complex I (FHL1) [17]. Members of this group are oxygen-sensitive, membrane-bound and are largely restricted to the facultatively fermentative Proteobacteria, particularly enterobacteria associated with animal intestinal tracts $[25,26]$. FHL-1 couples the reduction of protons from water to the anaerobic oxidation of formate to form $\mathrm{CO}_{2}$ and $\mathrm{H}_{2}[26,31]$.

BlastP and tBlastN analyses of the protein sequences encoded in the P. thermoglucosidasius DSM $2542^{\mathrm{T}}$ hydrogenase loci showed that the Pha, Phb and Phc loci are universally present in eight other $P$. thermoglucosidasius strains for which genomes are available (Additional file 2: Table S1). These loci are highly syntenous and the encoded proteins share average amino acid identities of 99.73\% ([Ni-Fe]-group 1d hydrogenase Pha-13 proteins), 99.61\% ([Ni-Fe]-group 2a hydrogenase Phb-16 proteins) and $99.22 \%$ ([Ni-Fe]-group 4a hydrogenase Phc-12 proteins) with those of DSM $2542^{\mathrm{T}}$, respectively. Pairwise BlastP analyses showed limited orthology between the two uptake hydrogenase loci, with $36.29 \%$ 
average amino acid identity in nine proteins encoded on the two loci. The group 1d (Pha) and group 2a (Phb) uptake hydrogenase loci share 33.40 and $62.32 \%$ average amino acid identity for three proteins with the $\mathrm{H}_{2}$ evolving hydrogenase (Phc) locus. The higher level of orthology for Phb and Phc loci proteins can be correlated with the HypA-like (PhbB and PhcK) and the HypB-like (PhbC and $\mathrm{PhcL}$ ) proteins, which share 75.22 and $86.08 \%$ amino acid identity, respectively, and are predicted to play a role in the incorporation of nickel into the hydrogenase enzyme [32]. Limited orthology is observed between the hydrogenase catalytic subunits or other hydrogenase formation and maturation proteins, suggesting distinct evolutionary histories for the two uptake and one $\mathrm{H}_{2}$-evolving hydrogenases in $P$. thermoglucosidasius.

\section{P. thermoglucosidasius contains a unique profile of hydrogenases with distinct evolutionary histories}

The proteins encoded by the Pha, Phb and Phc loci were used in BlastP comparisons against the NCBI nonredundant (nr) protein database and HydDB (catalytic subunits) to identify orthologous loci in other bacterial taxa. This revealed that, aside from the $\alpha$-proteobacteria Azospirillum halopraeferens DSM $3675^{\mathrm{T}}$ and Rhodopseudomonas palustris BAL398, the combination of [Ni-Fe] group 1- 2- 4 hydrogenases appears to be unique to $P$. thermoglucosidasius (Fig. 2). In these two proteobacterial taxa the group 2a uptake hydrogenase is, however, replaced by a group $2 \mathrm{~b}$ uptake hydrogenase. Group $2 \mathrm{~b}$ uptake hydrogenases do not have a direct role in energy transduction but are flanked by a PAS domain protein which accepts the hydrogenase-liberated electrons, modulating the activity of a two-component regulator that upregulates the expression of other uptake hydrogenases, thereby serving as $\mathrm{H}_{2}$-sensing system [33, 34].

The Pha uptake hydrogenase locus is relatively well conserved among members of the Firmicutes, including a number of taxa belonging to the Classes Bacilli, Clostridia and Negativicutes, as well as the phyla Proteobacteria and Bacteroidetes (Fig. 2; Additional file 3). However, the more distantly related taxa retain little synteny with the Pha locus in $P$. thermoglucosidasius (Fig. 3a). Orthologues of the Pha are present in one other Parageobacillus spp., namely genomosp.
NUB3621, with an average amino acid identity of 92.37\% (13 proteins) with the DSM $2542^{\mathrm{T}}$ Pha proteins. A phylogeny on the basis of nine conserved Pha proteins (PhaABCDGHIJK) showed a similar branching pattern (Fig. 3a) as observed for the phylogeny housekeeping protein (InfB-RecN-RpoB) phylogeny, suggesting that this is an ancestral locus that has been vertically maintained. This is supported by the low level of discrepancy in G+C content for the P. thermoglucosidasius strains, which are on average $0.87 \%$ above the genomic $\mathrm{G}+\mathrm{C}$ content. Larger discrepancies are, however, evident among the Bacteroidetes, where $\mathrm{G}+\mathrm{C}$ contents for the locus are on average $4.43 \%$ above that of the genome, and the absence of Pha loci in other Parageobacillus spp. including $P$. toebii (five genomes available) and $P$. caldoxylosilyticus (four genomes available) and Geobacillus spp. suggest a more complex evolutionary history for the group 1d hydrogenase.

Orthologous [Ni-Fe] group 2a uptake hydrogenase (Phb) loci are also common among the Firmicutes, but show a more restricted distribution within the family Bacillaceae, with only Aeribacillus pallidus $8 \mathrm{~m} 3$ and Hydrogenibacillus schlegelii DSM $2000^{\mathrm{T}}$ containing orthologues outside the genus Parageobacillus. Highly conserved and syntenous loci are, however, present in three non-thermoglucosidasius strains: Parageobacillus sp. NUB3621, Parageobacillus sp. W-2 and P. toebii DSM 18751 (Fig. 3b; Additional file 3). Orthologous loci are present across a much wider range of phyla than the Pha locus, including members of the Chloroflexi, Gemmatimonadetes, Actinobacteria, Proteobacteria, Nitrospirae and Deinococcus-Thermus (Fig. 2). The latter is of interest as Thermus thermophilus SG0.5JP17-16 clusters with the Firmicutes in a phylogeny of ten conserved proteins (PhbBCDEFHJLMN-72.76\% average amino acid identity with $P$. thermoglucosidasius DSM $2542^{\mathrm{T}}$ ) (Fig. 3b), but is phylogenetically disparate from the Firmicutes. The T. thermophilus locus is present on the plasmid pTHTHE1601 (NC_017273) suggesting that this locus forms part of the mobilome. Furthermore, the $\mathrm{G}+\mathrm{C}$ content of the Phb locus differs by an average of $4.55 \%$ from the average genomic $\mathrm{G}+\mathrm{C}$ among the eight compared $P$. thermoglucosidasius strains, suggesting recent horizontal acquisition of this locus.

(See figure on next page.)

Fig. 2 Prevalence of [Ni-Fe] hydrogenases orthologous to those in P. thermoglucosidasius among other bacterial taxa. The ML phylogeny was constructed on the basis of the trimmed alignment (1597 amino acids in length) of the concatenated InfB, RecN and RpoB amino acid sequences. Different taxa and branch colours indicate the different phyla/classes. Values on the branches indicate bootstrap values $(n=500$ replicates) and the tree was rooted on the midpoint. The presence of [Ni-Fe] group 1d, group 2a and group 4a hydrogenases is represented by dark blue, red and green blocks, respectively. Where [Ni-Fe] hydrogenases belonging to the same groups but not the same subtype as those in P. thermoglucosidasius are present they are indicated by light blue ([Ni-Fe] group 1 hydrogenases), pink ([Ni-Fe] group 2 hydrogenases) and light green ([Ni-Fe] group 4 hydrogenases) blocks, respectively 


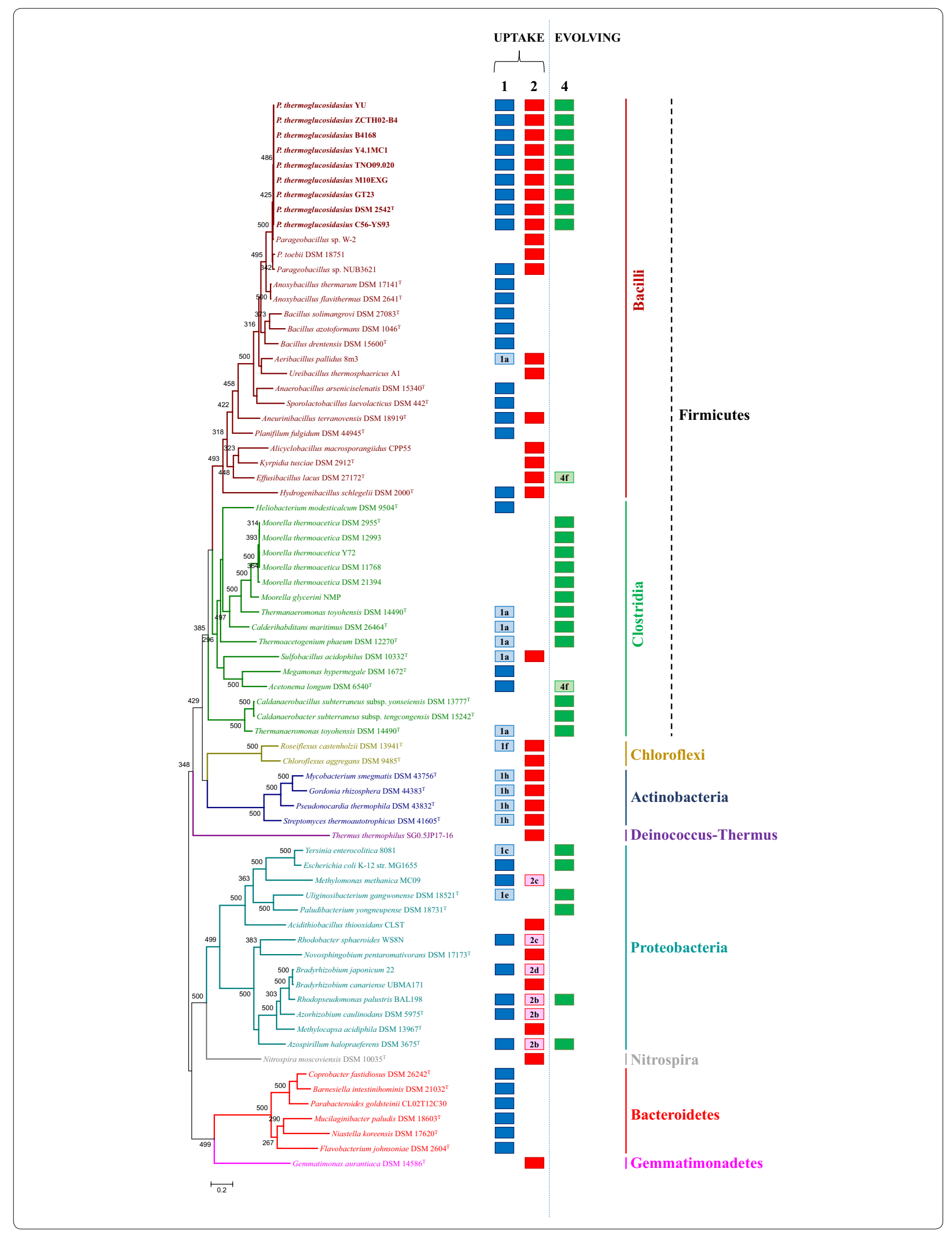




\section{a [Ni-Fe] group 1d hydrogenase - Pha}
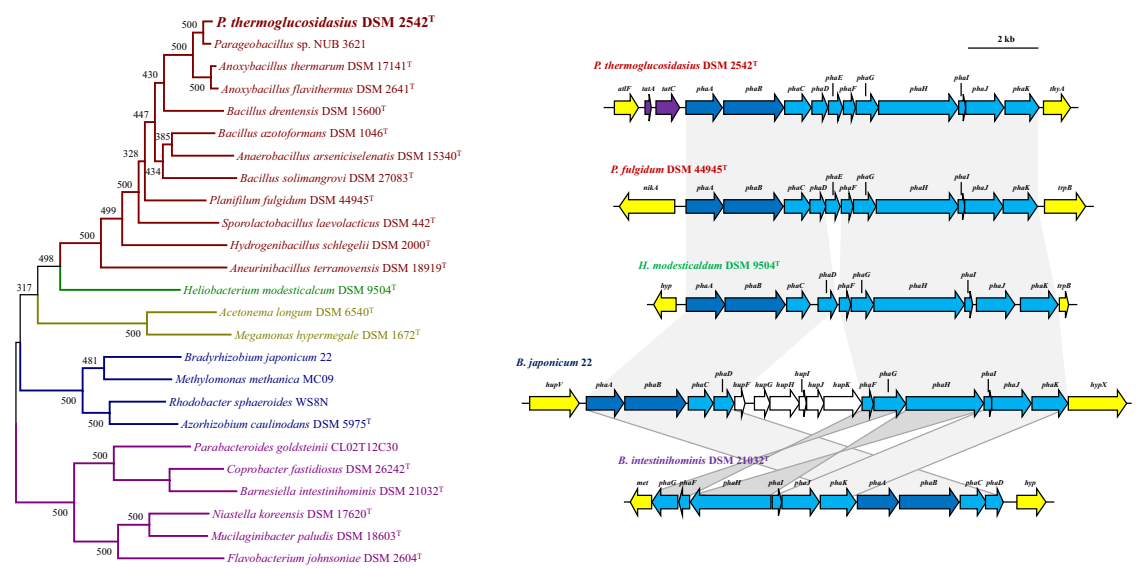

$\longmapsto 0.2$

b [Ni-Fe] group 2a hydrogenase - Phb
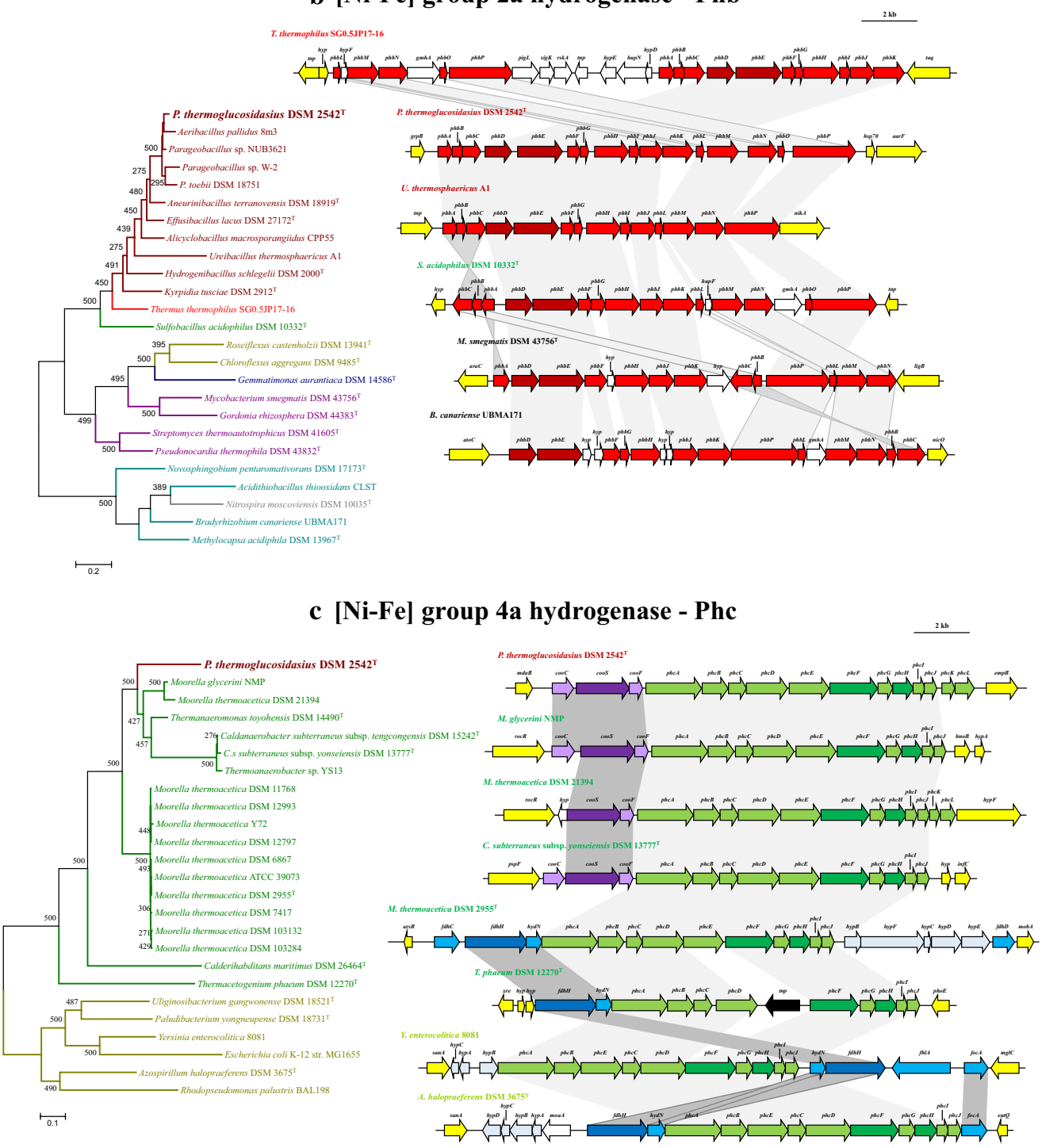
(See figure on previous page.)

Fig. 3 Prevalence and synteny of the P. thermoglucosidasius-like [Ni-Fe] hydrogenases. a $[\mathrm{Ni}$-Fe] group $1 \mathrm{~d}$ orthologues. The ML phylogeny was determined on the basis of the trimmed alignment of nine Pha locus proteins (PhaABCDGHIJK—2206 amino acids in length). Hydrogenase genes are coloured in light blue (dark blue for large and small catalytic subunits), tatAE genes in purple and flanking genes in yellow in the synteny diagrams. $\mathbf{b}$ [Ni-Fe] group 2a orthologues. The ML phylogeny was determined on the basis of the trimmed alignment of 10 Phb locus proteins (PhbBCDEFHJLMN - 2348 amino acids in length). Hydrogenase genes are coloured in red (dark red for large and small catalytic subunits), genes of no known function in biosynthesis and functioning of the hydrogenase in white and flanking genes in yellow in the synteny diagrams. $\mathbf{c}$ [Ni-Fe] group 4a orthologues. The ML phylogeny was determined on the basis of the trimmed alignment of nine Phc locus proteins (PhCABCDFGHIJ_2744 amino acids in length). Hydrogenase genes are coloured in light green (dark green for large and small catalytic subunits), anaerobic CODH genes in purple, formate dehydrogenase-related genes in blue and flanking genes in yellow in the synteny diagrams. Values on all trees reflect bootstrap analyses ( $\mathrm{n}=500$ replicates) and all trees were rooted on the midpoint

The [Ni-Fe] group 4a $\mathrm{H}_{2}$-evolving hydrogenase (Phc) locus shows the most restricted distribution of the three loci among the Firmicutes, with orthologous loci only present in the eight compared $P$. thermoglucosidasius strains and members of the clostridial family Thermoanaerobacteraceae (Fig. 2). Further, Phc-like loci appear to be restricted to members of the Proteobacteria. High levels of synteny and sequence conservation can be observed among the Phc loci in both phyla, with the exception of the PhcK and PhcL proteins, which are only present in the $P$. thermoglucosidasius and Moorella thermoacetica DSM 21394 Phc loci (Fig. 3c). BlastP analyses indicate that PhcK and PhcL show highest orthology with PhbB and PhbC in the Phb locus and may have been derived through gene duplication events.

It is notable that the P. thermoglucosidasius Phc locus clusters with a subset of the Thermoanaerobacteraceae in the concatenated Phc protein phylogeny, including Moorella glycerini NMP, M. thermoacetica DSM 21394, Thermoanaeromonas toyohensis DSM $14490^{\mathrm{T}}$, Caldanaerobacter subterraneus subsp. tencogensis DSM $15242^{\mathrm{T}}$ and subsp. yonseiensis DSM $13777^{\mathrm{T}}$ and Thermoanaerobacter sp. YS13 (Fig. 3c). These differ from the remaining Thermoanaerobacteraceae taxa and the proteobacterial orthologous loci in that they are flanked by three genes, cooCSF, coding for an anaerobic carbon monoxide (CO) dehydrogenase, rather than genes coding for a formate dehydrogenase $(\mathrm{FdhH})$ as is typical for the [Ni-Fe] group 4a hydrogenases [25]. These are generally accompanied by flanking genes coding for the formate dehydrogenase accessory sulfurtransferase protein FdhD, electron transporter HydN, transcriptional activator FhlA and formate transporters FdhC and FocA, which together with FdhH drive the anaerobic oxidation of formate (Fig. 3c) [26, 35-37].

BlastP analysis with the $\mathrm{FdhH}$ protein of $M$. thermoacetica DSM $2955^{\mathrm{T}}$ (AKX95035) shows that an orthologue is present in P. thermoglucosidasius DSM $2542^{\mathrm{T}}$ (ALF09582). The latter protein, however, shares limited orthology (39\% amino acid identity; Bitscore: 497; E-value: 6e-614) with its $M$. thermoacetica counterpart and is furthermore localised $\sim 1.5 \mathrm{Mb}$ upstream of the
Phc locus, suggesting the $P$. thermoglucosidasius FdhH protein does not function together with the [Ni-Fe] group 4 a hydrogenase. Instead, the $P$. thermoglucosidasius Phc hydrogenase may form a novel complex with the adjacent anaerobic CODH locus.

\section{The $P$. thermoglucosidasius [Ni-Fe] group 4 a hydrogenase forms a novel complex with the anaerobic (Coo) CO dehydrogenase, with a distinct evolutionary history} The three genes located just upstream of the $\mathrm{Phc}$ hydrogenase locus, $\operatorname{coo} C, \operatorname{coos}$ and $\operatorname{coo} F$ code for a $\mathrm{CO}$ dehydrogenase maturation factor (Figs. 3c, 4), a CO dehydrogenase catalytic subunit and $\mathrm{CO}$ dehydrogenase $\mathrm{Fe}-\mathrm{S}$ protein, respectively. Together these proteins catalyse the oxidation of $\mathrm{CO}$ to generate $\mathrm{CO}_{2}\left(\mathrm{CO}+\mathrm{H}_{2} \mathrm{O} \rightarrow \mathrm{CO}_{2}+2\right.$ $\left.\mathrm{H}^{+}+2 \overline{\mathrm{e}}\right)$. The electrons are then used in reduction reactions, including sulphate reduction, heavy metal reduction, acetogenesis, methanogenesis and hydrogenogenesis [38, 39].

The CODH locus is also co-localised with the Phc hydrogenase locus and highly conserved among the eight other $P$. thermoglucosidasius genomes $(99.36 \%$ average amino acid identity with CooCSF in $P$. thermoglucosidasius DSM $2542^{\mathrm{T}}$ ), while no CODH orthologues are encoded on the genomes of any other Parageobacillus or Geobacillus spp. A phylogeny on the basis of the conserved $\mathrm{CooS}$ and CooF proteins (Fig. 4) showed that, as with the Phc locus phylogeny (Fig. 3c), those taxa where cooCFS flanks the Phc hydrogenase locus cluster together and show extensive synteny in both the coo and phc gene clusters. This would suggest the co-evolution of the anaerobic $\mathrm{CODH}$ and $\mathrm{Phc}[\mathrm{Ni}-\mathrm{Fe}]$ group 4a hydrogenase loci. However, differences in the $\mathrm{G}+\mathrm{C}$ contents could be observed among the $P$. thermoglucosidasius coo (average $\mathrm{G}+\mathrm{C}$ content $46.97 \%$ ) and phc (average $\mathrm{G}+\mathrm{C}$ content $49.02 \%)$ loci. This is even more pronounced among the Thermoanaerobacteraceae with this $\mathrm{CODH}-\mathrm{Phc}$ arrangement, where the $\mathrm{G}+\mathrm{C}$ contents of the two loci differs by an average of $6.62 \%$ and is particularly evident in $C$. subterraneus subsp. tencongensis where the $\mathrm{G}+\mathrm{C}$ contents of the coo and phc loci differ by $11.77 \%$, suggesting independent evolution of these two loci. This is further 


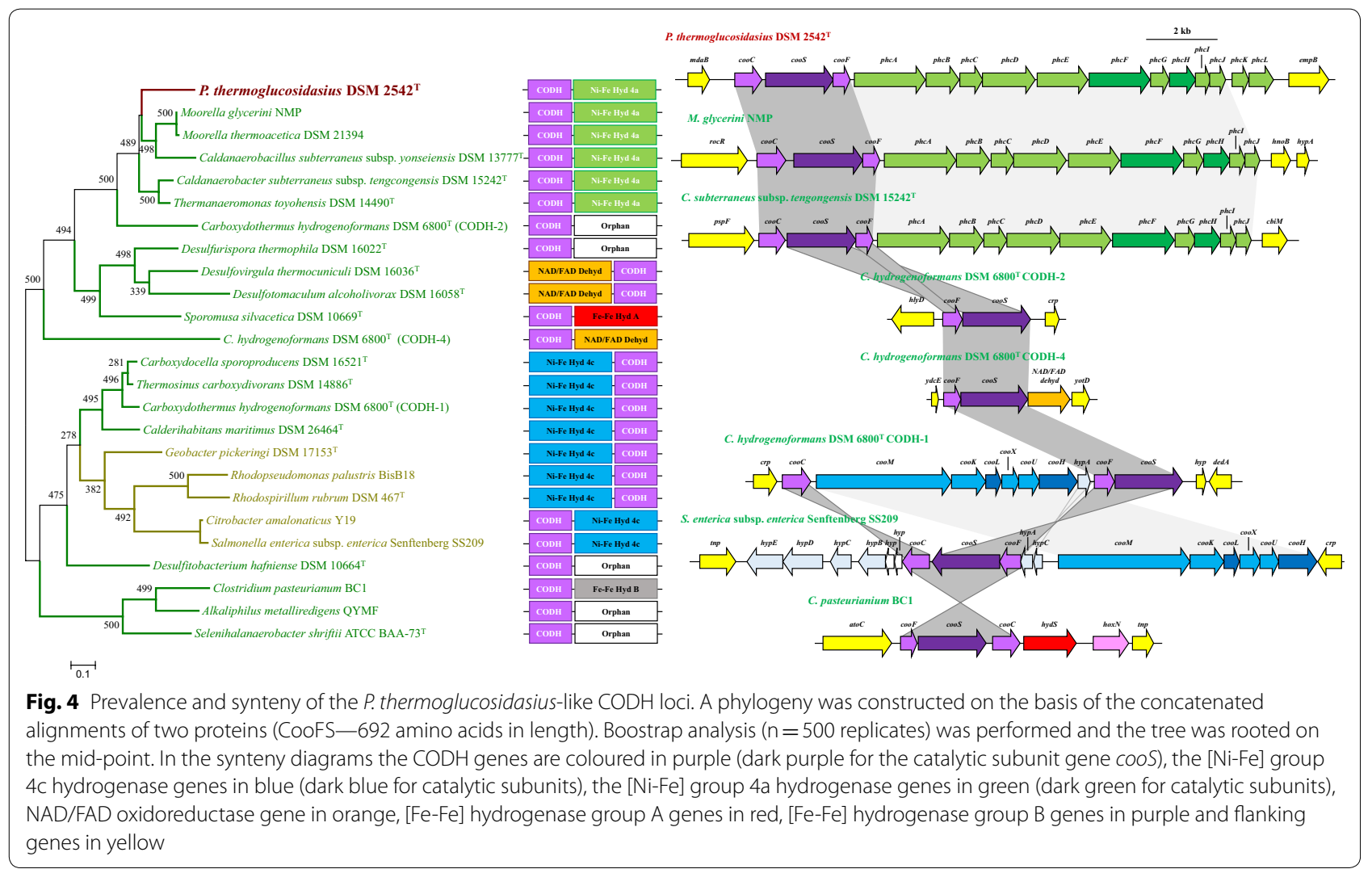

support by the phylogeny (Fig. 4), where the CODHPhc loci cluster with CODHs which appear on their own and those flanked by an NAD/FAD oxidoreductase are thought to play a role in oxidative stress response [40]. The Energy Conserving Hydrogenase (ECH-[Ni-Fe] group 4c hydrogenase)-CODH complex, which has been shown to couple $\mathrm{CO}$ oxidation to proton reduction to $\mathrm{H}_{2}$ in C. hydrogenoformans and Rhodospirillum rubrum, clusters more distantly from the $\mathrm{CODH}-[\mathrm{Ni}-\mathrm{Fe}]$ group 4a complex $[41,42]$. Overall, the results suggest that the $\mathrm{CODH}$ and $[\mathrm{Ni}-\mathrm{Fe}]$ group 4a hydrogenase have evolved independently, but may form a complex linking $\mathrm{CO}$ oxidation to reduction of protons to produce $\mathrm{CO}_{2}$ and $\mathrm{H}_{2}$.

\section{The CODH-[Ni-Fe] group 4a hydrogenase complex} effectively couples $\mathrm{CO}$ oxidation to hydrogenogenesis

The predicted function of the co-localized genes encoding the anaerobic $\mathrm{CODH}$ and $\mathrm{H}_{2}$-evolving hydrogenase (Fig. 3c) was tested using P. thermoglucosidasius DSM $2542^{\mathrm{T}}$. Two related strains, Geobacillus thermodenitrificans DSM $465^{\mathrm{T}}$ and P. toebii DSM $14590^{\mathrm{T}}$, which lack both orthologues of the three hydrogenases and the anaerobic $\mathrm{CODH}$, were included as controls. The cultivation of P. thermoglucosidasius DSM $2542^{\mathrm{T}}$ in serum bottles with a gas atmosphere consisting of 50\% CO and 50\% air showed that this strain was able to effectively grow in the presence of $50 \% \mathrm{CO}$, reaching a maximum absorbance of 0.82 after $6 \mathrm{~h}$ of cultivation (Fig. 5). A fractional amount of $\mathrm{CO}$ was consumed at the beginning of the experiment, when oxygen was still available, by $P$. toebii DSM $14590^{\mathrm{T}}(0.37 \mathrm{mmol})$ and G. thermodenitrificans DSM $465^{\mathrm{T}}(0.216 \mathrm{mmol})$, respectively. This suggests that these strains may possess an alternative mechanism, such as an aerobic $\mathrm{CO}$ dehydrogenase, where $\mathrm{CO}$ oxidation is coupled to an electron transport chain which finally reduces oxygen [38]. For instance, a predicted aerobic CODH is present (CoxMSL-OXB91742-744) in P. toebii DSM $14590^{\mathrm{T}}$ but is absent from G. thermodenitrificans DSM $465^{\mathrm{T}}$.

While the two control strains tolerated the presence of $\mathrm{CO}$, no $\mathrm{H}_{2}$ production was observed for either strain (Figs. 6 and 7). By contrast GC analyses revealed the production of $\mathrm{H}_{2}$ by $P$. thermoglucosidasius DSM $2542^{\mathrm{T}}$ after $\sim 36 \mathrm{~h}$ (Fig. 8). This corresponds with $\mathrm{O}_{2}$ reaching a 


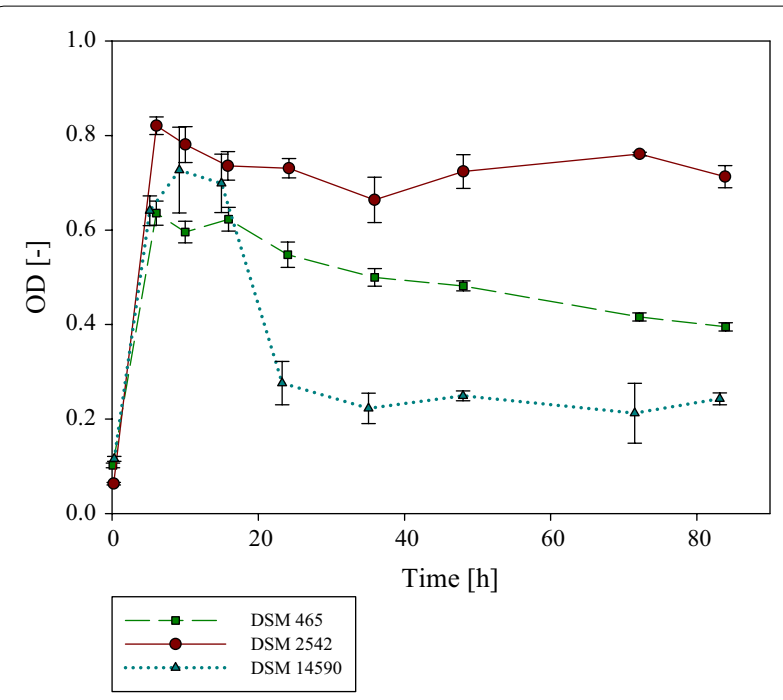

Fig. 5 Growth curves of P. thermoglucosidasius DSM $2542^{\top}, P$. toebii DSM $14590^{\top}$ and G. thermodenitrificans DSM $465^{\top}$. All strains were grown in quadruplicate in stoppered serum bottles with an initial gas atmosphere composition of 50\% CO and 50\% air. P. thermoglucosidasius DSM $2542^{\top}$ reached a maximum absorbance $\left(\mathrm{OD}_{600}=0.82\right)$ after $6.01 \mathrm{~h}$, by the end of the cultivation the $\mathrm{OD}_{600}$ increased to a value of 0.71. A maximum absorbance for P. toebii DSM $14590^{\top}$ was reached after $9.12 \mathrm{~h}\left(\mathrm{OD}_{600}=0.73\right)$. The $\mathrm{OD}_{600}$ decreased during the cultivation to a final value of 0.24 . For $\mathrm{G}$. thermodenitrificans DSM 465 the highest $\mathrm{OD}_{600}=0.64$ was observed after $6.04 \mathrm{~h}$. The $\mathrm{OD}_{600}$ decreased to a final value of 0.40

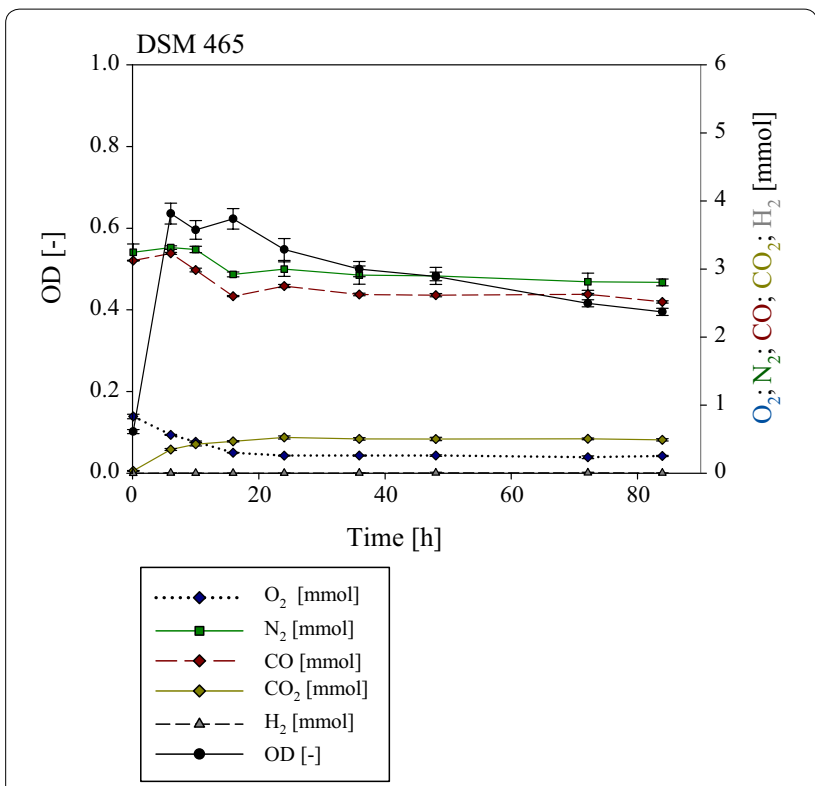

Fig. 7 Gas phase composition during the cultivation of $G$. thermodenitrificans DSM 465. Initial gas composition was 50\% CO and $50 \%$ air. $\mathrm{O}_{2}$ (dark blue) decreased from 0.83 to $\sim 0.03 \mathrm{mmol}$ after 24.01 h. CO (dark red) decreased fractionally about $0.22 \mathrm{mmol}$. No hydrogen (dark grey) was detected. $\mathrm{CO}_{2}$ (dark yellow) increased during the cultivation to $0.49 \mathrm{mmol}$. After $6.04 \mathrm{~h}$ a maximum absorbance $\left(\mathrm{OD}_{600}\right.$ in black) with a value of 0.64 could be detected

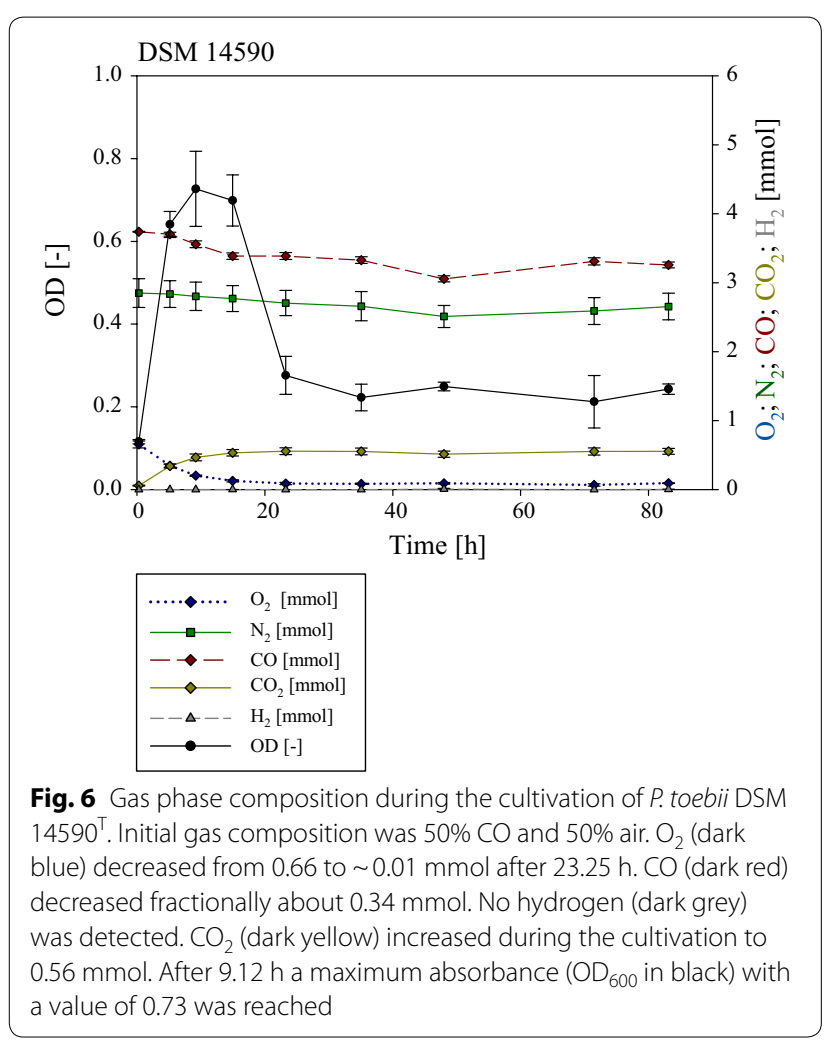

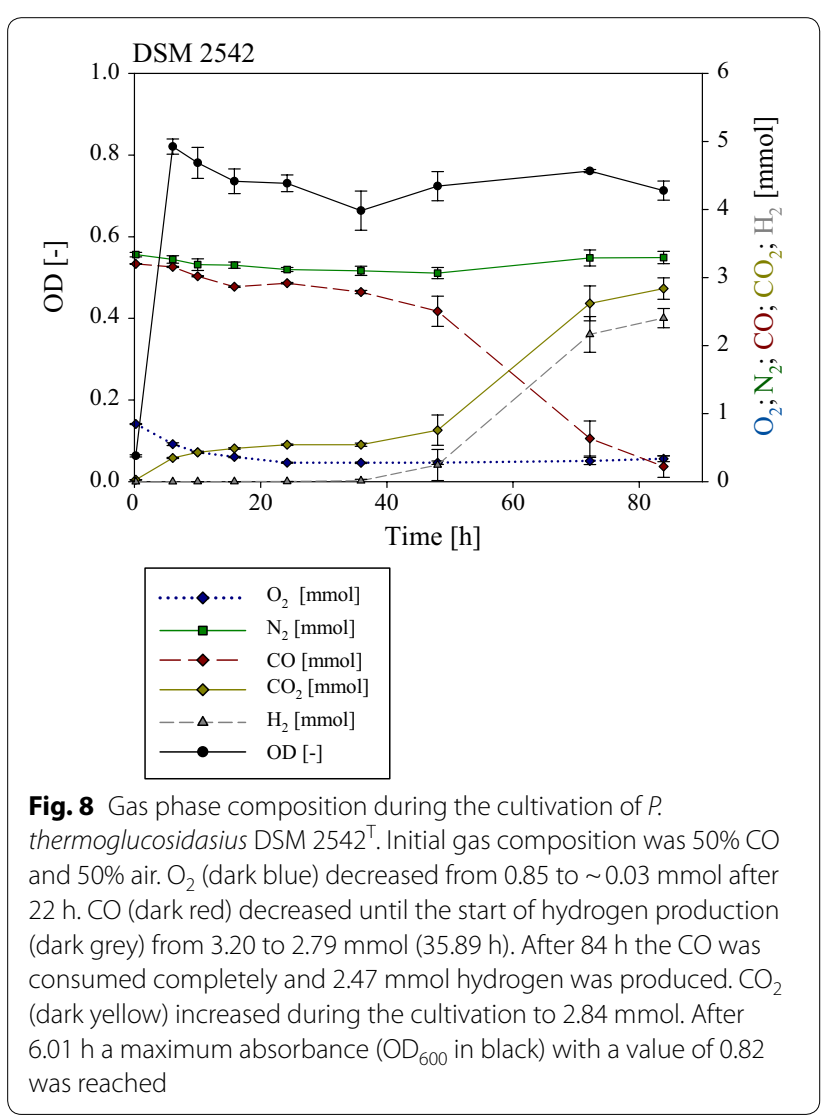


plateau value of $\sim 0.03 \mathrm{mmol}$. After $84 \mathrm{~h} 2.28 \mathrm{mmol} \mathrm{CO}$ was consumed and $2.47 \mathrm{mmol} \mathrm{H}_{2}$ produced. P. thermoglucosidasius DSM $2542^{\mathrm{T}}$ is thus capable of producing $\mathrm{H}_{2}$ at a near equimolar conversion to $\mathrm{CO}$ consumption once most residual oxygen has been exhausted with a final yield of $1.08 \mathrm{H}_{2} / \mathrm{CO}$.

\section{Discussion}

The redox potential and diffusion coefficient of molecular $\mathrm{H}_{2}$ make it a key component of metabolism and a potent energy source for many microbial taxa [25]. The ability to utilize this energy source relies on the production of various hydrogenase enzymes, which power both the consumption and production of $\mathrm{H}_{2}$ and inextricably couple $\mathrm{H}_{2}$ to energy-yielding pathways such as acetogenesis, methanogenesis and respiration [26, 43]. Our comparative genomic analysis revealed that $P$. thermoglucosidasius contains a unique hydrogenase compliment comprised of two uptake hydrogenases (group 1d and 2a) and one $\mathrm{H}_{2}$-evolving hydrogenase (group 4a). Evolutionary analysis showed that these hydrogenases are derived through three independent evolutionary events. This indicates that $\mathrm{H}_{2}$ is likely to play a pivotal role in $P$. thermoglucosidasius metabolism and bioenergetics in the ecological niches it occupies. By contrast, members of the sister genus Geobacillus lack orthologous hydrogenase loci and, aside from $P$. thermoglucosidasius, only the group $1 \mathrm{~d}$ and $2 \mathrm{a}$ uptake hydrogenases share orthology in one and three Parageobacillus spp., respectively, even though they are frequently isolated from the same environments.

The group $4 \mathrm{a}_{2}$-evolving hydrogenase of $P$. thermoglucosidasius is not found in any other members of the class Bacilli and is most closely related to those found in members belonging to the class Clostridia, particularly the family Thermoanaerobacteraceae. Furthermore, it forms an association with a $\mathrm{CODH}$, which is found in common with a more restricted subclade of strict anaerobes within the family Thermoanaerobacteraceae. Our fermentation studies with $P$. thermoglucosidasius in the presence of $\mathrm{CO}$ showed that $P$. thermoglucosidasius grows efficiently when exposed to high concentrations of $\mathrm{CO}$ and that the $\mathrm{CODH}$ group 4a hydrogenase complex can effectively couple $\mathrm{CO}$ oxidation to $\mathrm{H}_{2}$ evolution, $P$. thermoglucosidasius can do so at a near-equimolar conversion. Furthermore, unlike other $\mathrm{CO}$ oxidizing hydrogenogenic bacteria, which are strict anaerobes, $P$. thermoglucosidasius is a facultative anaerobe capable of first removing residual oxygen from $\mathrm{CO}$ gas sources prior to producing $\mathrm{H}_{2}$ via the water-gas shift reaction. The combination of these features makes $P$. thermoglucosidasius an attractive target for potential incorporation in industrial-scale production strategies of biohydrogen.

\section{Additional files}

Additional file 1. Calculation of the gas composition. Description of the calculation of the gas composition by using the ideal gas law.

Additional file 2. Annotations of the $\mathrm{CODH}$ and [Ni-Fe] hydrogenase loci of $P$. thermoglucosidasius DSM $2542^{\top}$. The locus tags, sizes, protein names as well as the functions of the proteins in the three [Ni-Fe] hydrogenase loci and the anaerobic CODH locus of P. thermoglucosidasius DSM $2542^{\top}$. BlastP data (locus tag, average amino acid identity, bitscore and e-value) for the closest non-Parageobacillus orthologue and the top conserved domain for each $P$. thermoglucosidasius DSM $2542^{\top}$ protein are shown.

Additional file 3. Orthologous [Ni-Fe] hydrogenase and anaerobic $\mathrm{CODH}$ loci in Parageobacillus and other taxa. The locus size, G+C content, G+C deviation of the orthologous [Ni-Fe] hydrogenase and anaerobic $\mathrm{CODH}$ loci of other P. thermoglucosidasius strains and distinct taxa as used in Figs. 2, 3 and 4. The number of protein orthologous and average amino acid identity of these proteins to those encoded on the P. thermoglucosidasius DSM $2542^{\top}$ loci are indicated.

\section{Authors' contributions}

TM planned the experiments, collected and analyzed the experimental data. HA, PM, SP and TM conducted the genomic analysis. RK conducted his Bachelor thesis under the supervision of $\mathrm{MZ}$ and $\mathrm{AN}$. AN and DC substantially contributed to conception and design of the experiments. AN, HA, PM and TM drafted the manuscript. All authors read and approved the final manuscript.

\section{Author details}

${ }^{1}$ Section II: Technical Biology, Institute of Process Engineering in Life Science, Karlsruhe Institute of Technology, 76131 Karlsruhe, Germany. ${ }^{2}$ Centre for Microbial Ecology and Genomics, University of Pretoria, Hatfield 0028 Pretoria, South Africa. ${ }^{3}$ School of Molecular \& Cell Biology, Faculty of Science, University of the Witwatersrand, WITS 2050 Johannesburg, South Africa. ${ }^{4}$ Section II: Technical Biology, Institute of Process Engineering in Life Science, Karlsruhe Institut für Technologie (KIT), Kaiserstrasse 12, 76131 Karlsruhe, Germany.

\section{Acknowledgements}

TM was supported by the Federal Ministry of Education and Research (Grant \#031B0180). PDM was funded by the National Research Foundation of South Africa (Grant \#109137). HA acknowledges funding from Alexander von Humboldt Foundation.

\section{Competing interests}

The authors declare that they have no competing interests.

Availability of data and supporting materials

All the data can be found within the article and its additional files.

Consent for publication

All the authors agree to submission.

Ethics approval and consent to participate

Not applicable.

Funding

We acknowledge support by Deutsche Forschungsgemeinschaft and Open Access Publishing Fund of Karlsruhe Institute of Technology.

\section{Publisher's Note}

Springer Nature remains neutral with regard to jurisdictional claims in published maps and institutional affiliations.

Received: 8 May 2018 Accepted: 2 July 2018

Published online: 09 July 2018 


\section{References}

1. International Energy Agency. World Energy Outlook 2017. 2017. https:// www.iea.org/weo2017. Accessed 26 Mar 2018.

2. Nikolaidis P, Poullikkas A. A comparative overview of hydrogen production processes. Renew Sustain Energy Rev. 2017;67:597-611.

3. Hosseini S, Wahid M. Hydrogen production from renewable and sustainable energy resources: promising green energy carrier for clean development. Renew Sustain Energy Rev. 2016;57:850-66.

4. Claassen PAM, van Lier JB, Lopez Contreras AM, van Niel EWJ, Sijtsma L, Stams AJM, et al. Utilisation of biomass for the supply of energy carriers. Appl Microbiol Biotechnol. 1999;52:741-55.

5. Kothari R, Buddhi D, Sawhney RL. Comparison of environmental and economic aspects of various hydrogen production methods. Renew Sustain Energy Rev. 2008;12:553-63.

6. Sokolova TG, Henstra AM, Sipma J, Parshina SN, Stams AJM, Lebedinsky AV. Diversity and ecophysiological features of thermophilic carboxydotrophic anaerobes. FEMS Microbiol Ecol. 2009;68:131-41.

7. Kim MS, Bae SS, Kim YJ, Kim TW, Lim JK, Lee SH, et al. CO-dependent $\mathrm{H}_{2}$ production by genetically engineered Thermococcus onnurineus NA1. Appl Environ Microbiol. 2013:79:2048-53.

8. Barnard D, Casanueva A, Tuffin M, Cowan D. Extremophiles in biofuel synthesis. Environ Technol. 2010;31:871-88.

9. Maness PC, Weaver PF. Hydrogen production from a carbon-monoxide oxidation pathway in Rubrivivax gelatinosus. Int J Hydrogen Energy. 2002;27:1407-11.

10. Diender M, Stams AJM, Sousa DZ, Robb FT, Guiot SR. Pathways and bioenergetics of anaerobic carbon monoxide fermentation. Front Microbiol. 2015;6:1-18.

11. Wang J, Wan W. Effect of temperature on fermentative hydrogen production by mixed cultures. Int J Hydrogen Energy. 2008;33:5392-7.

12. Oelgeschlaeger E, Rother M. Carbon monoxide-dependent energy metabolism in anaerobic bacteria and archaea. Arch Microbiol. 2008;190:257-69.

13. Techtmann SM, Colman AS, Robb FT. 'That which does not kill us only makes us stronger': the role of carbon monoxide in thermophilic microbial consortia. Environ Microbiol. 2009:11:1027-37.

14. Merrouch M, Hadj-Saïd J, Domnik L, Dobbek H, Léger C, Dementin S, et al. $\mathrm{O}_{2}$ inhibition of $\mathrm{Ni}$-containing $\mathrm{CO}$ dehydrogenase is partly reversible. Chem Eur J. 2015;21:18934-8.

15. Juszczak A, Aono S, Adams MW. The extremely thermophilic eubacterium, Thermotoga maritima, contains a novel iron-hydrogenase whose cellular activity is dependent upon tungsten. J Biol Chem. 1991;266:13834-41.

16. Tirado-Acevedo O, Chinn MS, Grunden AM. Production of biofuels from synthesis gas using microbial catalysts. Adv Appl Microbiol. 2010;70:57-92.

17. Søndergaard D, Pedersen CNS, Greening C. HydDB: a web tool for hydrogenase classification and analysis. Sci Rep. 2016;6:1-8.

18. Grant JR, Stothard P. The CGView Server: a comparative genomics tool for circular genomes. Nucleic Acids Res. 2008;36:181-4.

19. Besemer J, Lomsadze A, Borodovsky M. GeneMarkS: a self-training method for prediction of gene starts in microbial genomes. Implications for finding sequence motifs in regulatory regions. Nucleic Acids Res. 2001;29:2607-18

20. Hall TA. Bioedit: a user-friendly biological sequence alignment editor and analysis program for Windows 95/98/NT. Nucleic Acids Symp Ser. 1999;41:95-8.

21. Wallace IM, Sullivan OO, Higgins DG, Notredame C. M-Coffee: combining multiple sequence alignment methods with T-Coffee. Nucleic Acids Res. 2006;34:1692-9.

22. Talavera G, Castresana J. Improvement of phylogenies after removing divergent and ambiguously aligned blocks from protein sequence alignments. Syst Biol. 2007;56:564-77.
23. Guindon S, Gascuel O. A simple, fast, and accurate algorithm to estimate large phylogenies by maximum likelihood. Syst Biol. 2003;52:696-704

24. Lefort V, Longueville J, Gascuel O. SMS: smart model selection in PhyML. Mol Biol Evol. 2017;34:2422-4

25. Greening C, Biswas A, Carere CR, Jackson CJ, Taylor MC, Stott MB, et al. Genomic and metagenomic surveys of hydrogenase distribution indicate $\mathrm{H}_{2}$ is a widely utilised energy source for microbial growth and survival. ISME J. 2016;10:761-77.

26. Vignais PM, Billoud B. Occurrence, classification, and biological function of hydrogenases: an overview. Chem Rev. 2007;107:4206-72.

27. Sargent F, Bogsch EG, Stanley NR, Wexler M, Robinson C, Berks BC, et al. Overlapping functions of components of a bacterial Sec-independent protein export pathway. EMBO J. 1998;17:3640-50.

28. Dutta D, De D, Chaudhuri S, Bhattacharya SK. Hydrogen production by cyanobacteria. Microb Cell Fact. 2005;4:36-46.

29. Esteves-Ferreira AA, Cavalcanti JHF, Vaz MGMV, Alvarenga LV, Nunes-Nesi A, Araújo WL. Cyanobacterial nitrogenases: phylogenetic diversity, regulation and functional predictions. Genet Mol Biol. 2017:40:261-75.

30. Holmqvist M, Lindberg P, Agervald Å, Stensjö K, Lindblad P. Transcript analysis of the extended hyp-operon in the cyanobacteria Nostoc sp. strain PCC 7120 and Nostoc punctiforme ATCC 29133. BMC Res Notes. 2011:4:186.

31. Andrews SC, Berks BC, McClay J, Ambler A, Quail MA, Golby P, et al. A 12-cistron Escherichia coli operon (hyf) encoding a putative proton-translocating formate hydrogenlyase system. Microbiology. 1997;143:3633-47.

32. Chan K-H, Lee K-M, Wong K-B. Interaction between hydrogenase maturation factors HypA and HypB is required for [NiFe]-hydrogenase maturation. PLoS ONE. 2012;7:e32592.

33. Lenz $\mathrm{O}$, Friedrich $\mathrm{B}$. A novel multicomponent regulatory system mediates $\mathrm{H}_{2}$ sensing in Alcaligenes eutrophus. Proc Natl Acad Sci. 1998;95:12474-9.

34. Vignais PM, Elsen $\mathrm{S}$, Colbeau A. Transcriptional regulation of the uptake [NiFe] hydrogenase genes in Rhodobacter capsulatus. Biochem Soc Trans. 2005;33:28-32.

35. Maier T, Binder U, Böck A. Analysis of the hydA locus of Escherichia coli: two genes (hydN and hypF) involved in formate and hydrogen metabolism. Arch Microbiol. 1996:165:333-41.

36. Mukherjee M, Vajpai M, Sankararamakrishnan R. Anion-selective formate/ nitrite transporters: taxonomic distribution, phylogenetic analysis and subfamily-specific conservation pattern in prokaryotes. BMC Genomics. 2017:18:1-19.

37. Thomé R, Gust A, Toci R, Mendel R, Bittner F, Magalon A, et al. A sulfurtransferase is essential for activity of formate dehydrogenases in Escherichia coli. J Biol Chem. 2012;287:4671-8.

38. Ragsdale SW. Life with carbon monoxide. Crit Rev Biochem Mol Biol. 2004;39:165-95.

39. Techtmann SM, Lebedinski AV, Colman AS, Sokolova TG, Woyke T, Goodwin $\mathrm{L}$, et al. Evidence for horizontal gene transfer of anaerobic carbon monoxide dehydrogenases. Front Microbiol. 2012;3:1-16.

40. Wu M, Ren Q, Durkin AS, Daugherty SC, Brinkac LM, Dodson RJ, et al. Life in hot carbon monoxide: the complete genome sequence of Carboxydothermus hydrogenoformans Z-2901. PloS Genet. 2005;1:e60.

41. Fox JD, Kerby RL, Roberts GP, Ludden PW. Characterization of the CO-induced, CO-tolerant hydrogenase from Rhodospirillum rubrum and the gene encoding the large subunit of the enzyme. J Bacteriol. 1996;178:1515-24

42. Soboh B, Linder D, Hedderich R. Purification and catalytic properties of a $\mathrm{CO}$-oxidizing: $\mathrm{H}_{2}$-evolving enzyme complex from Carboxydothermus hydrogenoformans. Eur J Biochem. 2002;269:5712-21.

43. Schwartz E, Fritsch J, Friedrich B. $\mathrm{H}_{2}$-metabolizing prokaryotes. In: Rosenberg E, DeLong EF, Lory S, Stackebrandt E, Thomson F, editors. The prokaryotes: prokaryotic physiology and biochemistry. Berlin: Springer; 2013. p. 119-99. 